\title{
Perilaku Bisnis Islami Tao Zhu Gong : Sebuah Pembelajaran ('Ibrah)
}

\author{
Wiwid Aditya Nugroho \\ Magister Manajemen, \\ Sekolah Pascasarjana Universitas HAMKA, Jakarta \\ E-mail: wiwidnugroho@yahoo.com
}

\begin{abstract}
ABSTRAK
Bisnis sudah menjadi bagian kehidupan orang Cina yang tidak dapat terpisahkan. Hal ini pula yang menjadikan mereka sebagai salah satu sumber ilmu bisnis terpercaya karena kesuksesannya telah terbukti diseluruh dunia. Salah satunya adalah Tao Zhu gong yang mempunyai nama asli Fan li merupakan orang kepercayaan kaisar yue, yaitu Gou jian sekitar abad 500 SM. Tao Zhu-gong seorang ahli strategi militer yang mengundurkan diri dari kedudukan tinggi seorang perdana mentri untuk menjadi seorang pebisnis dan milyuner pertama di China. Karyanya yang terkenal adalah Kaidah emas keberhasilan Bisnis. Penelitian ini mencoba untuk membahas tentang 12 prinsip bisnis menurut Tao Zhu-gong. serta bagaimana 12 prinsip bisnis Tao Zhu-gong dalam perspektif Islam. Dengan menggunakan metode dokumentasi dan metode pendekatan historis (historical approach) penulis berkesimpulan bahwa sebagian dari 12 prinsip bisnis menurut Tao Zhu-gong mengandung nilai-nilai Islam, dan sebagian lainnya tidak sesuai dengan nilai Islam, disebabkan ketiadaan nilai spiritual didalamnya.
\end{abstract}

Kata Kunci: Prinsip, Bisnis Islam, Pembelajaran ('Ibrah)

\section{Pendahuluan}

Bisnis adalah bagian kehidupan orang Cina yang tidak dapat terpisahkan. Orang Cina bisa berbisnis dimana saja termasuk di kawasan yang paling tidak produktif sekalipun. Hal ini senada dengan ungkapan bahwa "Orang Cina bisa berbisnis di kampong Melayu, tetapi orang Melayu belum tentu bisa berbisnis di 
kawasan orang cina”. Kita memang dapat melihat bahwa orang Cina memang mudah berkembang dimana saja. Lihat saja di kota-kota yang ada di Indonesia, pengusaha Cina berkembang pesat. Bahkan kini mereka menguasai perekonomian dunia melalui sektor bisnis.

Hal ini pula yang menjadikan mereka sebagai salah satu sumber ilmu bisnis terpercaya karena kesuksesannya telah terbukti diseluruh dunia. Kesuksesan orang-orang cina berbisnis dan berbisnis di berbagai pelosok dunia merupakan sebuah fenomena yang menakjubkan (Than, 2008: v). Kesuksesan orang Cina yang hidup di abad modern bergantung kepada filosofi referensi, dan literaturliteratur klasik serta ajaran-ajaran para tokoh Cina kuno (Permadi \& Kuswahyono, 2007: 4). Salah satunya adalah Tao Zhu gong yang dipercaya sebagai seorang miliuner pertama di China sebelum masehi.

Orang china memilih Tao Zhu gong sebagai panutan mereka dalam berbisnis, karena Tao zhu gong mempunyai prinsip bisnis unik dan terkenal yang masih dipakai oleh keluarga bisnis china hingga saat ini.

\section{Biografi Tao Zhu Gong}

Tao Zhu Gong yang mempunyai nama asli Fan li adalah orang kepercayaan Kaisar "Yue", yaitu Gou jian sekitar abad 500 SM (Young, 2002: 6). Beliau juga ahli strategi ketika terjadi peperang antara Kaisar "Yue" dan Kaisar "Wu" Karena tidak mengikuti nasihat fan li, tahun 498 SM Gou Jian dan keluarganya ditangkap dan dijadikan budak oleh kaisar Wu, Fu Chai selama beberapa tahun, gou jian bekerja di kandang kuda dan merawat Kuda-kuda Fu Chai. Karena kebaikan sikapnya, Gou Jian Akhirnya diizinkan pulang. Kepulangan Gou jian menandai masa mulainya Fan Li membantu Gou jian merencanakan perebutan kembali wilayah kekuasaan yang hilang.

Salah satu strateginya adalah memanfaatkan gadis China yang kecantikannya sangat terkenal untuk menaklukan Fu Chai. Menyadari bahwa Fu Chai memiliki kelemahan terhadap wanita cantik, Xi Shi, yang dikenal sebagai salah satu dari 4 wanita cantik cina kuno, dikirim sebagai selir kaisar. Selama diam di Kerajaan $\mathrm{Wu}$, Xi Shi bertindak sebagai mata-mata Yue, yang membantu Menyulut Perpecahan antara $\mathrm{Fu}$ Chai dan Jenderalnya yang sangat pintar dan sangat 
dipercayainya, $\mathrm{Wu} \mathrm{Zi} \mathrm{Xu}$. Akhirnya Fu Chai kehilangan kerajaannya, direbut kembali oleh Gou Jian Dan mengangkat Fan Li atau Tao Zhu gong sebagai Ahli Militer.

Penilaiannya yang sangat hebat terhadap karakter tidak sampai pada menolong Gou Jian memperoleh kembali kerajaannya. Fan LI mampu mengenali bahwa Gou Jian memang pemimpin hebat untuk bekerja sama dalam masa-masa sulit, tetapi bukan tuan yang baik di masa jaya dan damai. Fan LI mengundurkan diri dari tugasnya di pengadilan. Sebelum pergi, ia bahkan memperingatkan sahabat dekatnya akan bahayanya mengabdi Gou Jian karena zaman telah merubah. Sayangnya, teman baiknya tidak mendengarkannya dan akhirnya dihukum mati oleh Gou Jian (Munarman, 2011: 15).

Fan li mengembara ke berbagai daerah di Cina, tetapi akhirnya menetap dan menjadi seorang pengusaha. Belakangan dia mengganti namanya menjadi Tao zhu-gong. Karena hebat menilai karakter, dia tidak mengalami kesulitan dalam berhubungan dengan orang lain dan suka memperoleh kepercayaan mereka. Tidak heran ia menjadi sangat sukses. Dia dikenal umum sebagai multi-milioner pertama di cina. Banyak ilmuwan china tidak mengetahui kapan dia wafat, akan tetapi sebagian mereka mengatakan Tao Zhu gong atau Fan LI tutup usia di usianya yang ke 70 tahun.

\section{Dua Belas (12) Prinsip Bisnis Tao Zhu Gong}

Dan karya beliau yang sangat populer adalah 12 Prinsip Bisnis. Dan prinsipprinsip tersebut adalah sebagai berikut:

\subsection{Kemampuan Mengenal orang}

Pengusaha cina selalu mementingkan hubungan (guanxi) $^{1}$ dan rasa percaya (xin yu) dalam kesepakatan bisnis. Kepercayaan bisa terbantu oleh pengenalan dari teman, kepercayaan harus dibangun dengan berbagi makanan dan bertukar informasi, orang china menghabiskan banyak waktu untuk menentukan

${ }^{1}$ Guanxi merupakan ikatan atas dasar hubungan keluarga, klan ataupun tempat kelahiran. Guanxi juga terjadi karena adanya persamaan nasib di perantauan. 
kepercayaan orang lain, maka apabila terjadi perselisihan, perbedaan, dan pertikaian sulit bagi orang cina untuk bekerja sama kembali (Malvin, 2008: 102).

Tao zhu gong mengingatkan agar bersikap tegas dan jelas dalam melakukan negosiasi dalam berdagang. sehingga semua serba pasti. Maka cermat dalam menjalankan kontrak perjanjian menjadi suatu keharusan (Tjoe, 2008: 81).

\subsection{Kemampuan menangani orang}

Pada dasarnya ada dua jenis pembeli; pertama, pembeli yang belum pernah masuk toko. Kedua, adalah pembeli yang sering masuk toko (Oei: 59). Dalam berbisnis orang tionghoa sangat memahami pelanggan. Pelanggan adalah pembawa rezeki atau Gangdow. Dan layanan sangat penting untuk mengembangkan bisnis karena apabila layanannya buruk maka kualitas barangnya pun buruk bahkan negative (Oei: 81).

Prinsip layanan adalah mau memberi sebelum menerima, memberi tidak selamanya dengan uang, bahkan bisa gratis, contohnya: memberi senyum, tidak marah saat pembeli emosi, bila perlu mengalah dengan pembeli (Oei: 85).

\subsection{Fokus dalam berbisnis}

Pada awalnya lazim tidak diperkenankan untuk berganti-ganti bisnis, akan tetapi dianjurkan untuk tekun pada satu bisnis dulu, fokus memberi arah yang lebih pasti kemana bisnis akan bergerak. Jika bergerak dalam begitu banyak usaha dan tidak fokus, akan sulit menemukan kekuatan dan identitas bisnis atau usaha, serta membuat bisnis menjadi terbuka (Chivita, 2010: 50).

\subsection{Kemampuan organisasi}

Tao zhu gong menyadari bahwa memajang dan mengemas produk dengan baik bisa menarik pelanggan, dan membantu meningkatkan nilai produk. Berdasarkan prinsip ini menunjukan perlunya membentuk kesan yang sangat baik terhadap toko untuk dapat menonjolkan produk kualitas tinggi dan tawaran pelayanan yang menyenangkan (Hou, 2001).

Namun sebaliknya para pedagang china sangat lemah dalam menampilkan dan mengemas toko maupun produk. Akibatnya produk mereka dianggap memiliki 
harga murah dibanding pesaingnya dari barat. Karena mereka gagal memanfaatkan prinsip ini.

3.5.Bersikap tangkas dan fleksibel

Orang cina dikenal sebagai bangsa yang fleksibel, mudah berubah, dan menyesuaikan diri dengan keadaan apa pun. Salah satu kepandaian orang cina, mereka biasa berdagang dimana saja. Lihat saja Kota-kota di Indonesia, para pengusaha cina berkembang begitu pesat (Emsan, 2011: 66-67). Hal ini senada dengan suatu ungkapan bahwa orang cina bisa berdagang di kampong melayu, tetapi orang melayu belum tentu bisa berdagang di kawasan orang china (Nugraha, 2008: 99).

Namun bukan berarti mereka tidak pernah mengalami kegagalan dalam menjalankan bisnis. Mereka mengevaluasi segala kekurangan, kelemahan, kesalahan, dan kegagalan. Mereka pun yakin bahwa seseorang tidak akan gagal selamanya (Emsan, 2011: 67). Kegagalan pertama membuat mereka semakin semangat, kegagalan -kedua dijadikan pelajaran, kegagalan ketiga menjadikannya lebih bijak, dan kegagalan keempat dan seterusnya untuk menguji kesabaran dan ketabahannya (Than, 2008: 59).

\subsection{Kemampuan menagih pembayaran}

Tao zhu gong mengetahui bahwa untuk memajukan dan mengembangkan usaha, harus memiliki keuangan yang kuat. Diantaranya adalah kemampuan untuk menagih pembayaran. Tanpa adanya pemasukan dan surplus keuangan maka tidak akan mampu memberi kepuasan kepada pemilik saham (Nugraha, 2008: 99).

\subsection{Kemampuan menempatkan sumber daya manusia}

Dalam konteks perusahaan, memilih orang yang tepat akan menjamin penyelesaian tugas. Orang yang dipilih bukan hanya orang yang berkemampuan tetapi juga dapat diandalkan. Salah satu cara orang tersebut dapat diandalkan adalah dengan memastikan pekerjaan tersebut sesuai dengan kebutuhan, kemampuan, kesenangan, kemahiran, dan tantangan yang disukai. Karena jika tidak sesuai maka orang tersebut akan kehilangan minat dan bosan (Hou, 2001: 146).

\subsection{Kemampuan berbicara}


Didalam berdagang diharuskan menerapkan kejujuran. Mereka percaya bahwa perbuatan yang tidak jujur akan menyebabkan penyelewengan (Adi Susilo: 151). Orang cina memperhitungkan kepuasan pelanggan dan kejujuran. Jika ada masalah, harus cepat-cepat diselesaikan agar tidak berbuah keburukan yang semakin merugikan dikemudian hari (Tjoe, 2008: 84).

\subsection{Kemampuan dalam pembelian}

Didalam penawaran dianjurkan untuk menawar sampai tiap onsnya karena hal tersebut akan menguntungkan pebisnis didalam penjualan barang tersebut kembali.

\subsection{Kemampuan memanfaatkan peluang}

Agar bisnis bisa diutung diperlukan ketajaman membaca peluang. Orang tionghoa lihai membaca peluang bisnis di stiap perubahan dan memanfaatkan peluang sebaik mungkin asalkan tidak merugikan pihak lain (Oie: 20-21).

3.11. Kemampuan memulai dan menjadi contoh

Orang China selalu tepat waktu dan berdisiplin di dalam bekerja. Disiplin dikaitkan dengan harga diri. Jika mengalami kegagalan, maka bukan organisasi dan perusahaan yang menanggung malu tetapi kehilangan harga diri. Jadi untuk menjaganya mereka harus memastikan keberhasilan organisasi dan perusahaan (Nugraha, 2008: 102).

\subsection{Kemampuan melihat jauh kedepan}

Untuk menjadi Pedagang yang berhasil, dituntut untuk memiliki wawasan dan pandangan jauh kedepan (Adi Susilo: 155). Berdagang merupakan kegiatan yang penuh resiko dan tidak ada jaminan bahwa orang itu akan untung. Karena itu, Orang China berani mengambil resiko. Mereka berusaha mengurangi resiko seminimal mungkin (Adi Nugroho, 100-101).

\section{Relevansi dengan Nilai-nilai Islam dalam Bisnis}

Tanpa kita sadari bahwasanya 12 Prinsip Tao Zhu Gong tersebut mengandung nilai-nilai Islam. Dan nilai-nilai Islam tersebut adalah sebagai berikut: 
1) Kemampuan Mengenal orang, mengetahui karakter orang akan menjamin keuangan usaha anda (neng shi ren: zhi ren shan e, zhang ти bu fu). Prinsip ini sesuai dengan firman Allah Swt. yang berbunyi:

"Hai manusia, Sesungguhnya Kami menciptakan kamu dari seorang laki-laki dan seorang perempuan dan menjadikan kamu berbangsa bangsa dan bersuku-suku supaya kamu saling kenal-mengenal. Sesungguhnya orang yang paling mulia diantara kamu disisi Allah ialah orang yang paling taqwa diantara kamu. Sesungguhnya Allah Maha mengetahui lagi Maha Mengenal”. (QS. Al-Hujurat: 13)

Didalam Islam, prinsip Ini berhubungan dengan silaturahmi, yaitu adanya ikatan persaudaraan (Guanxi). Sebagaimana Rasulullah Saw bersabda, "Barangsiapa yang mengiginkan keluasan rezeki dan kepanjangan umur, maka hendaknya bersilaturrahmi” (HR. Bukhari).

Silaturahim adalah suatu gambaran amalan atau perbuatan baik kepada kerabat sedarah atau lainnya, dengan memberikan kebaikan, serta saling memperhatikan. Ada kelebihan didalam silaturahim yaitu memperpanjang umur dan meluaskan rezeki (As-Sun'aniy : 294).

2) Kemampuan menangani orang, memperlakukan orang dengan rasa hormat akan membuat anda diterima dikalangan luas dan membuat bisnis berkembang. (neng jie na: li wen xiang dai, jiao guan zhe zhong). Dalam prinsip ini sesuai dengan menghormati orang lain dan melayaninya dengan ramah. Hal ini sama seperti menghormati tamu.

3) Kemampuan berfokus pada bisnis, mengabaikan yang lama untuk mendapatkan yang baru merupakan kutukan bisnis. (neng an ye: yan gu xi xin, shang gu da bing). Peneliti melihat bahwasanya prinsip tersebut mempunyai nilai istiqomah didalam bekerja. Hal ini sesuai dengan firman Allah Swt. dalam Al-qur'an:

"Sesungguhnya orang-orang yang mengatakan: "Tuhan Kami ialah Allah" kemudian mereka meneguhkan pendirian mereka, Maka 
Malaikat akan turun kepada mereka dengan mengatakan: "Janganlah kamu takut dan janganlah merasa sedih; dan gembirakanlah mereka dengan jannah yang telah dijanjikan Allah kepadamu". 31. Kamilah pelindung-pelindungmu dalam kehidupan dunia dan akhirat; di dalamnya kamu memperoleh apa yang kamu inginkan dan memperoleh (pula) di dalamnya apa yang kamu minta”. (QS. Al-Fushilat[41]: 30-31)

4) Kemampuan menggorganisasi, bila produk ditampilkan baik ia akan menarik perhatian banyak orang. (neng zhen dun: huo wu zheng qi, duo ren xin $\mathrm{mu}$ ). Islam melihat bahwasanya mengorganisasi yang baik merupakan salah satu faktor kesuksesan dalam bekerja. Dan telah disebutkan dalam suatu kata bijak yang menyatakan bahwa: "kebenaran yang tidak diorganisasi akan dikalahkan oleh kebathilan yang terorganisir. Demikianlah islam memperhatikan betapa pentingnya organisasi”.

5) Kemampuan bersikap tangkas dan fleksibel: keengganan dan keraguan akan menghasilkan kesia-siaan. (neng tao zhang: qin jin bu dai, qu tao zi duo). Prinsip ini sesuai dengan prinsip Islam yaitu kemampuan menyelesaikan pekerjaan dengan segera tanpa menunda pekerjaan tersebut. Allah SWT berkata didalam Al-qur'an:

"Dan bersegeralah kamu kepada ampunan dari Tuhanmu dan kepada surga yang luasnya seluas langit dan bumi yang disediakan untuk orangorang yang bertakwa” (QS. Ali-Imron[3]: 133)

Ayat tersebut analogikan dengan mengerjakan pekerjaan dengan segera dan tidak menunda pekerjaan tersebut. Akan tetapi ada perbedaan didalamnya yaitu: Islam menyuruh untuk segera mengerjakan pekerjaan dengan iman dan takwa, sedangkan Tao Zhu gong menyuruh tidak dengan keduanya melainkan hanya bertujuan materi semata.

6) Kemampuan menagih pembayaran, rajin dan rewel akan memberikan untung lebih bagi perusahaan. (neng tao zhang: Qin jin bu dai, qu tao zi $d u o$ ). Prinsip ini sedikit berbeda dengan Islam, karena Islam menyuruh mengikhlaskan semua hutang-hutang apabila si penghutang jatuh miskin dan 
tidak bisa membayar hutang-hutangnya. Sebagaimana Rasulullah Saw bersabda:

قال رسول الله صلى الله عليه وسلّم: رحم الله عبداً سمحاً إذا باع. سمحاً إذا

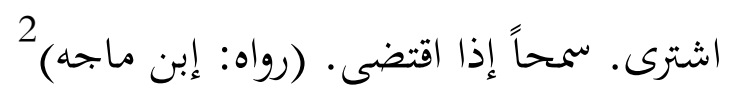

Hadist tersebut menjelaskan bahwasanya Allah akan memberikan rahmahnya kepada siapa saja yang memberikan kemudahan dalam berhutang.

7) Kemampuan mempekerjakan dan menempatkan sumber daya manusia dengan memilih orang yang tepat untuk pekerjaan yang tepat akan menjamin bahwa orang tersebut dapat dipercaya dan diandalkan. (neng yong ren: yin cai qi shi, ren shi you lai)

Prinsip ini sesuai dengan prinsip pembagian kerja dalam ekonomi Islam. Didalam Al-Qur'an telah dijelaskan bahwa kemampuan manusia terbatas dan perlu adanya pembagian kerja.

Apakah mereka membagi-bagi rahmat Tuhanmu? Kamilah yang menetukan penghidupan mereka dalam kehidupan dunia, dan Kami telah meninggikan sebagian mereka atas sebagian yang lain beberapa derajat, agar sebagian mereka dapat memanfaatkan sebagian yang lain. Dan rahmat Tuhanmu lebih baik dari apa yang mereka kumpulkan (QS. Adz-Zukhruf[43]: 32)

Prinsip ini mirip dengan Ibnu Khaldun seorang ulama Muslim dalam teorinya the division of labour, "seorang individu tidak akan dapat memenuhi kebutuhan ekonominya seorang diri, melainkan mereka harus bekerjasama dengan pembagian kerja dan spesialisasi”. Dan juga teori division of labour menurut adam smith (1729-1790), bahwa "pembagian

$$
\text { دار السلام)، ص. } 215 \text { إمام الحافظ أبى عبد الله محمّد بن يزيد الربّعى ابن ماجه القزوينى رحمه الله، جامع إبن ماجه، (الرياض: }
$$


kerja akan mendorong spesialisasi, dimana orang akan memilih mengerjakan yang terbaik sesuai dengan bakat dan kemampuannya masingmasing. Hal ini akan meningkatkan produktivitas tenaga kerja yang pada akhirnya akan meningkatkan hasil produksi secara total "3

8) Kemampuan berbicara, kepandaian berbicara bisa mendatangkan keberuntungan dan memberikan pencerahan kepada orang lain. (neng bian lun: zuo cai you dao, chan fa yu meng)

Diwajibkan kepada para pebisnis untuk bersikap jujur, tanggung jawab dan amanah. Karena apabila dia berbohong maka tidak akan pernah dipercaya kembali. Dan prinsip ini sesuai dalam Islam dalam kejujuran berbicara. Rasulullah SAW bersabda:

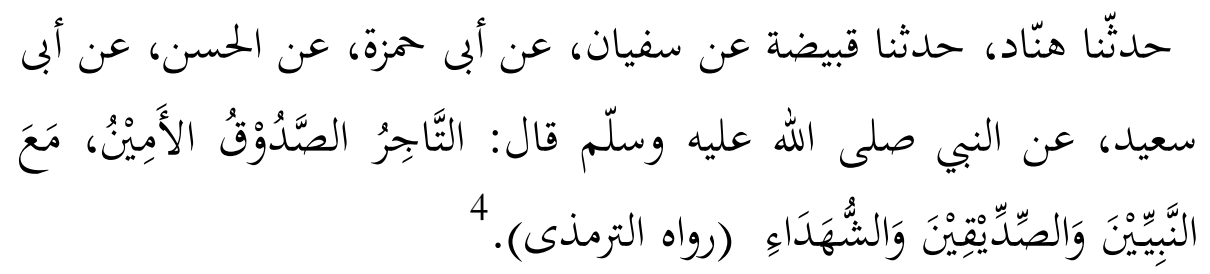

9) Kemampuan unggul dalam pembelian, dalam pembelian, menawar sampai tiap ons nya tidak akan mengurangi modal anda. Bahwasanya tawarmenawar diperbolehkan dalam Islam karena tawar-menawar merupakan jalan menuju kesepakatan Akad (perjanjian).

10) Prinsip ini menjelaskan bahwa pentingnya memanfaatkan waktu, barangsiapa yang menyianyiakan waktunya maka ia menghilangkan kehidupannya. Sebagaimana Allah berfirman dalam Al-Qur'an,

${ }^{3}$ Nur Chamid, Jejak Langkah Sejarah Pemikiran Ekonomi Islam, Yogyakarta:Pustaka Pelajar, 2010), hal. 252

$$
\begin{aligned}
& \text { 4إمام الحافظ أبى عيسى محمّد بن عيسى بن سورة ابن موسى الترمذى، الجامع الترمذى ، (الرياض: } \\
& \text { دار السلام 1420هـ-1999م)،ص. } 295
\end{aligned}
$$


"Demi masa. Sesungguhnya manusia itu benar-benar dalam kerugian, Kecuali orang-orang yang beriman dan mengerjakan amal saleh dan nasehat menasehati supaya mentaati kebenaran dan nasehat menasehati supaya menetapi kesabaran. (QS. Al-Ashr[103]: 1-3)

11) Kemampuan memulai dan menjadi contoh. Prinsip ini sesuai dengan prinsip islam yang dalam menjadi uswatun hasanah. Dan telah ada permisalannya yaitu Rasulullah Saw beliau adalah sebaik-baiknya uswah. ${ }^{5}$ Seperti yang dijelaskan dalam Al-Qur'an:

"Sesungguhnya telah ada pada (diri) Rasulullah itu suri teladan yang baik bagimu (yaitu) bagi orang yang mengharap (rahmat) Allah dan (kedatangan) hari kiamat dan Dia banyak menyebut Allah”. (QS. Al-Ahzab[33]: 21)

12) Kemampuan melihat jauh kedepan, kapan harus mencari lebih banyak, mengencangkan atau mengendurkan, tergantung pada situasi. (neng yuan shu: duo gua kuan jin, zhuo zhong er xing)

Prinsip ini merupakan bentuk dari perencanaan dan tidak dapat dipisahkan dari Islam. Allah Swt berfirman dalam Al-Qur'an:

"Dan Kami tidak menciptakan langit dan bumi dan apa yang ada antara keduanya tanpa hikmah. yang demikian itu adalah anggapan orang-orang kafir, Maka celakalah orang-orang kafir itu karena mereka akan masuk neraka.” (QS. Shaad[38]: 27)

Ayat tersebut menjelaskan bahwasanya didalam menciptakan alam semesta Allah Swt menciptakannnya dengan penuh perencanaan, maka manusia pun harus merencanakan sesuatu disetiap pekerjaannya. ${ }^{6}$

\section{Kesimpulan}

Pada akhirnya, penulis sampai pada kesimpulan bahwa 12 prinsip bisnis menurut Tao Zhu-gong terdiri dari kemampuan mengenal seseorang, kemampuan

${ }^{5}$ Dr. K.H, Didin Hafidhudin, M.Sc \& Hendri Tanjung, S.Si, M.M, Manajemen Syariah dalam Praktik, Jakarta: Gema Insani Press, 2003, hal. 120

${ }^{6}$ Dr. K.H, Didin Hafidhudin, M.Sc \& Hendri Tanjung, S.Si, M.M, Op-chit, hal, 79 
menghormati seseorang, kemampuan fokus terhadap bisnis, kemampuan menggorganisir, kemampuan bertindak tangkas dan fleksibel, kemampuan menagih hutang, kemampuan menempatkan SDM, kemampuan berbicara, kemampuan.unggul dalam pembelian, kemampuan melihat kesempatan, kemampuan menjadi contoh, kemampuan melihat ke depan. Sebagian dari 12 Prinsip Tao Zhu-gong telah mengandung nilai-nilai Islam diantaranya silaturahmi, menghormati sesama, istiqomah, menggorganisisr secara baik, tidak menunda pekerjaan, pembagian kerja, kejujuran, tawar menawar secara baik, pengaturan waktu, menjadi teladan yang baik, dan perencanaan yang matang.

Adapun yang tidak sesuai dengan nilai Islam, karena tidak adanya nilai spiritual didalamnya.

\section{Daftar Pustaka}

Imam al-Bukhari, Sahih Bukhari, (Riyadh: Darussalam, 1997 M-1417 H) Imam Ibnu Majah, Sunan Ibnu Majah, (Riyadh: Darussalam, 1999 M - 1420 H) Imam At-Tirmidzi, Jami’ At-Tirmidzi, (Riyadh: Darussalam, 1999 M - 1420 H) Muhammad Ibnu Isma'il As-Sun'iy, Subulussalam Syarhu Bulughul Maram Min Adillati al-Ahkam, (Al-Azhar: Darul Fikr, 2006)

Chivita, Tim, 7 Intisari Resep Kaya ala Orang China, 2010, Yogyakarta, Chivita Books.

Emsan, Rahasia Bisnis Orang Cina, Arab, dan India, 2011, Yogyakarta, DIVA Press.

Hafidhudin, Didin \& Hendri Tanjung, Manajemen Syariah dalam Praktik, 2003, Jakarta, Gema Insani Press.

Hou, Wee Chow, The Inspiration of Tao Zhu-gong Modern Business Lessons from an Ancient Past, 2001, Singapore, Prentice Hall.

Jenewa, Fakultas Organisasi Internasional MBA Universitas, Organisasi Pengusaha yang Efektive, 2006, Jakarta.

Kuswahyono, Iwan Permadi dan Imam, Penerapan Etika Bisnis Etnis Cina dalam Kompleksitas Persaingan Usaha: Perspektif Antropologi Hukum, 2007, Jurnal Aplikasi Manajemen, Volume 5, No. 1, April.

Malvin, Sheila, The Little Red Book of Cina Business Rahasia Berbisnis dengan Bangsa China, 2008, Bandung, Momentum.

Munarwan, Haikal, Resep Sukses Bisnis ala Orang China, 2011, Yogyakarta, Araska. 
Nugraha, Adi, Membaca Kepribadian Orang-Orang China, 2008, Yogyakarta, Garasi.

Oei, Istijanto, Rahasia Sukses Toko Tionghoa Mengembangkan Toko dari Nol \& Meraup Keuntungan Maksimal, Jakarta, Gramedia.

Than, Andreas Lee, Rahasia Kekayaan Orang-Orang Cina, 2008, Yogyakarta, Arti Bumi Intaran.

The Epoch Times International News, edition $122^{\text {nd }}, 13-19^{\text {th }}$ of November 2009.

Tjoe, Thomas Liem, Ilmu Bisnis Tionghoa Meramu Strategi Bisnis Sun Tzu Sampai Kebijakan Kong Fu Tze, 2008, Yogyakarta, Media Pressindo.

Young, Stephen B. Family Business and Reforms in Corporate Governance, 2002, Institute of Police Studies, Singapore.

http://lama.gatra.com/2001-06-04/versi_cetak.php?id=6762

http://pedemunegeri.com/tulisan/detail/1161/sedikit-cerita-tentang-rahasia-bisnisorang-cina-yg-bisa-kita-teladani 